\title{
Education Research: Physician identification and patient satisfaction on an academic neurology inpatient service
}

Christopher R. Leon Guerrero, MD, Tracy Anderson, BS, and Allyson R. Zazulia, MD

Neurology ${ }^{\circledR}$ 2018;90:e632-e636. doi:10.1212/WNL.0000000000004961
Correspondence

Dr. Zazulia

zazuliaa@wustl.edu

\section{Abstract \\ Objective}

To determine the relationship between neurology inpatient satisfaction and (1) number of physicians involved in the patient's care and (2) patients' ability to identify their physicians.

\section{Methods}

A 10-item questionnaire addressing patient satisfaction and identification of physicians on the care team was administered to patients admitted to an academic, tertiary care, inpatient neurology service from May 1 to October 31, 2012. We hypothesized higher satisfaction among patients having fewer physicians on the care team and among patients able to identify their physicians.

\section{Results}

A total of 652 patients were enrolled. An average of 3.9 (range 3-8) physicians were involved in each patient's care. Patients were able to correctly identify on average $2.4(60.7 \%)$ physicians involved in their care. Patients who were very satisfied correctly identified a larger percentage of physicians involved in their care $(63.8 \%$ vs $50.7 \%, p<0.001)$, were more likely to identify a physician who knew them best $(94.3 \%$ vs $43.6 \%, p<0.001)$ and who was "in charge" of their care $(94.1 \%$ vs $57.6 \%, p<0.001)$, and were more likely to have private insurance $(82.8 \%$ vs $70.5 \%, p<0.001)$ and fewer physicians involved in their care $(3.84$ vs $4.06, p=0.02)$.

\section{Conclusions}

Neurology inpatients' ability to identify physicians involved in their care is associated with patient satisfaction. Strategies to enhance patient satisfaction might target improving physician identification, reducing actual or perceived disparities in care based on payer status, and reducing handoffs or conducting handoffs at the bedside.

From the Department of Neurology (C.R.L.G.), George Washington University, Washington, DC; Department of Neurology (T.A.), Barnes-Jewish Hospital; and Departments of Neurology and Radiology (A.R.Z.), Washington University School of Medicine, St. Louis, MO.

Go to Neurology.org/N for full disclosures. Funding information and disclosures deemed relevant by the authors, if any, are provided at the end of the article. 


\section{Glossary}

BJH = Barnes-Jewish Hospital.

A challenge of academic neurology inpatient services is that the physician team caring for each patient typically involves numerous providers and trainees. In addition, restructuring of training programs to meet increasing duty hour restrictions over the last decade have resulted in a shift work model, leading to even more providers involved in a patient's care. With the current system of coverage, it is conceivable for a patient to be cared for by as many as 5 to 10 physicians even during a brief hospitalization. Prior evidence suggests that patients' satisfaction is influenced by their ability to form a personal relationship with their physician and is thus affected by their ability to identify their physicians and the physicians' role in their care. ${ }^{1,2}$ However, patients treated in an academic setting often cannot identify who their physicians are or their level of training. ${ }^{1,3,4}$

In this study, we sought to determine physician-related factors that may influence patient satisfaction on an inpatient academic neurology service as well as the relationship between patient satisfaction and physician identification. We hypothesized that (1) patients are more likely to be satisfied with their care when fewer physicians are involved in their care and (2) a patient's ability to identify the physicians involved in his or her care is associated with greater patient satisfaction.

\section{Methods}

We conducted a prospective survey of consecutive patients admitted to the adult neurology inpatient service at BarnesJewish Hospital (BJH), Washington University in Saint Louis, from May 1 to October 31, 2012. Patients had to be age 18 or older and admitted directly to the $\mathrm{BJH}$ neurology service from home, emergency department, or another hospital. Patients were excluded if they were cared for on another $\mathrm{BJH}$ service or in the neurocritical care unit prior to transfer to the neurology service, were admitted under 23-hour observation status or to the private neurology service, or were non-English-speaking. Patients with aphasia or cognitive impairment could participate if a family member familiar with their hospital care was present.

Cases were screened by daily review of the discharge board and new admission list, supplemented by discussion with senior neurology residents, charge nurse, and social worker, as needed. Eligible patients or the patient's caregiver were approached by a study team member not involved in the patient's care within 24 hours of anticipated discharge and invited to participate in the study. The Washington University School of Medicine institutional review board approved this study, and verbal informed consent was provided by all participants or their caregiver.

All participants completed a questionnaire consisting of items addressing their knowledge of who their physicians were; which physician (if any) they believed knew them the best after the hospital stay; which physician (if any) they believed to be in charge of their care; and their level of satisfaction with their physician team using a 5-point Likert scale regarding overall care, communication, involvement in decisions, and being seen by the physician when needed. Along with the questionnaire, participants were provided with a composite containing names and photographs of all neurology attendings, fellows, and residents working on the inpatient neurology service that month.

Clinical descriptive data including date of admission, date of discharge, neurology team (general or stroke), primary discharge diagnosis, discharge disposition, age, sex, and insurance status were collected from the patient's medical record. Names of all physicians on the neurology service who wrote daily notes or were directly involved in the patient's care were recorded. Involvement of medical students and consultation by other services was noted, as were names of other physician team members the patient might have seen on morning rounds.

Two-tailed unpaired $t$ tests were used to compare continuous variables, and Fisher exact test and $\chi^{2}$ tests were used for noncontinuous variables. Descriptive statistics were used to analyze the patient identification data. All analyses were performed using GraphPad Instat version 3.1a for Mac OS X GraphPad Software, San Diego, CA (graphpad.com).

\section{Results}

\section{Patient enrollment}

A total of 1,460 patients were admitted to the neurology service during the study period. Of the 722 eligible for participation, 652 patients were enrolled. Reasons for nonenrollment included discharge before being able to complete the survey $(\mathrm{n}=58)$ and refusal $(\mathrm{n}=12)$. A small fraction of the enrolled patients $(38 / 652)$ had the survey completed by a family member familiar with their hospital care.

\section{Physician identification}

An average of 3.9 (range 3-8) physicians were involved in each patient's care. Patients were able to correctly identify on average $2.4(60.7 \%)$ physicians involved in their care, and 93.2\% of patients were able to identify at least one physician involved in their care. Patients were most likely to identify the junior resident as knowing them best and to identify the attending physician as being "in charge" of their care (figure).

\section{Patient satisfaction}

Three quarters of the patients (494/652) answered "very satisfied" to all 4 survey questions related to satisfaction with care received by their physicians. 
Figure Results of a survey examining patient perceptions of various physicians involved in their care on a neurology inpatient service at an academic medical center

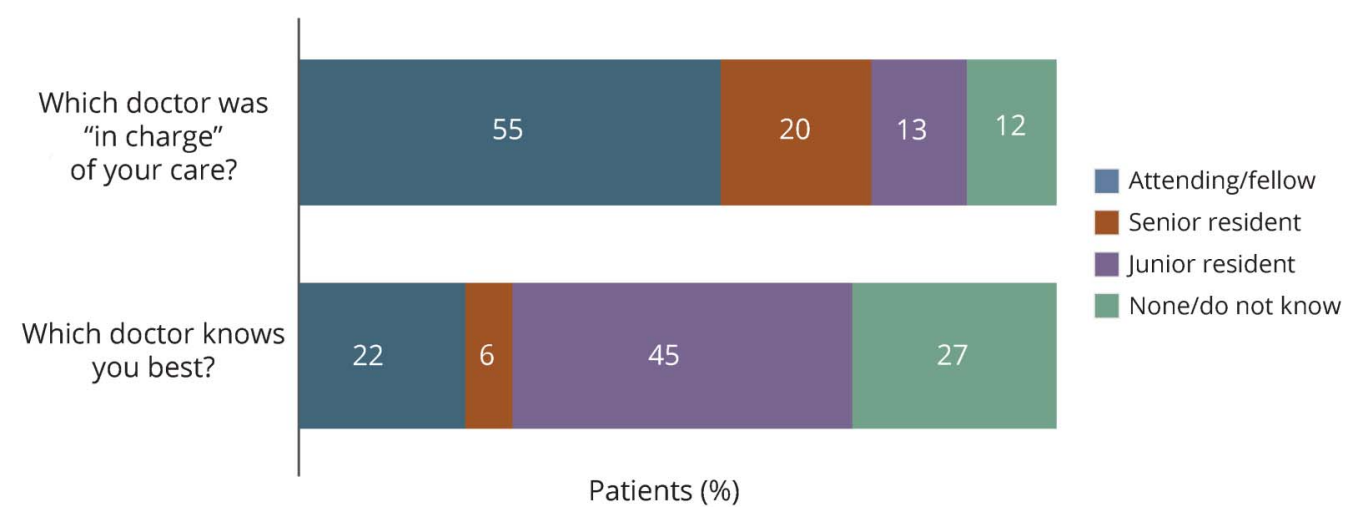

The majority of patients perceived the junior neurology resident as the doctor that knew them the best and the attending or fellow as the doctor "in charge" of their care.

Patients with private insurance were more likely to be very satisfied $(82.8 \%$ vs $70.5 \%, p<0.001)$. There was no difference in age, sex, length of stay, admission pathway, discharge disposition, primary diagnosis, student involvement, or person filling out the survey between the 2 groups (table).

Patients who were very satisfied were able to correctly identify a larger percentage of physicians involved in their care $(63.8 \%$ vs $50.7 \%, p<0.001)$, were more likely to identify a physician who knew them best (94.3\% vs $43.6 \%, p<0.001)$ and a physician who was in charge of their care ( $94.1 \%$ vs $57.6 \%, p$ $<0.001)$, and were more likely to have fewer physicians involved in their care (3.84 vs $4.06, p=0.02)$.

\section{Discussion}

In this study, we found a patient's satisfaction on an academic neurology inpatient service to be associated with their ability to identify the physicians involved in their care. In addition, we found associations between patient satisfaction and payer status and number of physicians involved in the patient's care.

The link between a patient's ability to identify the physicians involved in his or her care and degree of satisfaction is not surprising. Prior studies using open-ended questioning have found patients are rarely $(\sim 10 \%)$ able to identify at least one physician involved in their care. ${ }^{2,3}$ Using physician photograph composites, we achieved much greater identification in our study, with $93.2 \%$ of patients able to identify at least one physician, and on average, $60 \%$ of the physicians involved in their care. Indeed, providing patients with a photograph composite of providers may be a simple tool to improve patient satisfaction. $^{5-7}$ In addition, writing the names of the patient's providers in the room and structured/bedside handoffs are other simple interventions that may increase physician identification and ultimately improve patient satisfaction.
Satisfied patients were more likely to identify a physician who knew them best and a physician who was perceived to be "in charge" of their care, irrespective of the physician's level of training. Not unexpectedly, the junior resident, who typically has the most face-to-face interaction with the patient, was most likely to be correctly identified. Furthermore, the junior resident was the physician most likely to be perceived as knowing the patient best. Since most patients believe it is important to know the level of training of a physician involved in their care ${ }^{1}$ but a majority do not understand the training hierarchy or physician roles in a teaching hospital, ${ }^{3,4}$ further research is needed to determine the influence that improving this understanding would have on satisfaction with care.

We also found patient satisfaction was associated with private insurance status, which has been reported by others. ${ }^{8} \mathrm{We}$ cannot exclude the possibility of actual or perceived differential treatment based on insurance status as a contributor to this finding. Educating physicians about the implicit biases they may have and the influence of patients' perception of bias on their health care could help reduce any disparities in care provided and potentially translate into improved patient satisfaction.

Finally, we found a relationship between number of physicians involved in a patient's care and patient satisfaction. Although the absolute difference in number of physicians between patients who were very satisfied and those who were less than very satisfied is small (0.2), this finding highlights the influence that size of an academic team can have on overall patient satisfaction. While decreasing the number of physicians involved in a patient's care in the academic setting may not be feasible given work-hour restrictions and need for trainee supervision, minimizing unnecessary handoffs could mitigate a potential cause of patient dissatisfaction, as could performance of structured handoffs at the bedside. ${ }^{9}$ 
Table Predictors of patient satisfaction

\begin{tabular}{|c|c|c|c|}
\hline & Very satisfied & Less than very satisfied & $p$ Value \\
\hline Age, y, mean (SD) & $56.3(16.6)$ & $54.1(18.4)$ & 0.16 \\
\hline Sex, n (\%) & & & 0.14 \\
\hline Male $(n=315)$ & $247(78.4)$ & $68(21.5)$ & \\
\hline Female $(n=337)$ & $247(73.3)$ & $90(26.7)$ & \\
\hline Length of stay, $d$, mean (SD) & $3.2(2.0)$ & $3.3(1.7)$ & 0.50 \\
\hline Insurance status, n (\%) & & & $<0.001$ \\
\hline Private $(n=279)$ & $231(82.8)$ & $48(17.2)$ & \\
\hline Medicare/Medicaid/out-of-pocket $(n=373)$ & $263(70.5)$ & $110(29.5)$ & \\
\hline Admission pathway, $\mathrm{n}(\%)$ & & & 0.11 \\
\hline Emergency department $(n=400)$ & $306(76.5)$ & $94(23.5)$ & \\
\hline Transfer (outside hospital) $(n=180)$ & $128(71.1)$ & $52(28.9)$ & \\
\hline Direct admission $(n=72)$ & $60(83.3)$ & $12(16.6)$ & \\
\hline Discharge disposition, $\mathbf{n}(\%)$ & & & 0.79 \\
\hline Home $(n=468)$ & $351(75)$ & $117(25)$ & \\
\hline Inpatient rehabilitation $(n=148)$ & $115(77.7)$ & $33(22.3)$ & \\
\hline Skilled nursing facility $(n=34)$ & $26(76.5)$ & $8(23.5)$ & \\
\hline Primary diagnosis, $\mathbf{n}(\%)$ & & & 0.76 \\
\hline Vascular $(n=262)$ & $204(77.9)$ & $58(22.1)$ & \\
\hline Seizure $(n=82)$ & $60(73.2)$ & $22(26.8)$ & \\
\hline Headache/migraine $(n=47)$ & $36(76.6)$ & $11(23.4)$ & \\
\hline Multiple sclerosis/autoimmune $(n=37)$ & $28(75.7)$ & $9(24.3)$ & \\
\hline CNS infection $(n=26)$ & $18(69.2)$ & $8(30.8)$ & \\
\hline Nonepileptic seizure $(n=26)$ & $18(69.2)$ & $8(30.8)$ & \\
\hline Other $(n=162)$ & $130(80.2)$ & $32(19.8)$ & \\
\hline No. of physicians involved in care, mean (SD) & $3.8(1.0)$ & $4.0(1.2)$ & 0.02 \\
\hline Consultant involved in care, $\mathrm{n}(\%)$ & $120(24.3)$ & $35(22.2)$ & 0.67 \\
\hline Student involved in care, $\mathbf{n}(\%)$ & $46(9.3)$ & $14(8.9)$ & $>0.99$ \\
\hline Family member completing survey, $\mathrm{n}(\%)$ & $25(5.0)$ & $13(8.2)$ & 0.17 \\
\hline
\end{tabular}

Our study was limited to identification of physicians, so we cannot address the influence on satisfaction of ability to identify other members of the patient care team. However, others have demonstrated enhanced satisfaction with nursing communication via use of posted names and photographs of nurses, suggesting our findings are not specific to physician identification.?

On an academic neurology inpatient service, patients who were more satisfied with their care were better able to identify the physicians involved in their care. Minimizing handoffs and coverage changes along with simple interventions to improve patient recognition of their physicians are potential strategies to enhance patient satisfaction. Such strategies are becoming increasingly important as academic centers contend with restriction in duty hours and as reimbursement becomes linked to patient satisfaction.

\section{Author contributions}

Christopher R. Leon Guerrero is responsible for manuscript drafting, acquisition of the clinical data, and evaluating and interpreting the data. Tracy Anderson is responsible for acquisition of the clinical data and revising the manuscript for intellectual content. Allyson R. Zazulia is responsible for study concept and design, acquisition of the clinical data, analysis and interpretation of the data, and revising the manuscript for intellectual content. 


\section{Study funding}

No targeted funding reported.

\section{Disclosure}

The authors report no disclosures relevant to the manuscript. Go to Neurology.org/N for full disclosures.

\section{References}

1. Santen SA, Hemphill RR, Prough EE, Perlowski AA. Do patients understand their physician's level of training? A survey of emergency department patients. Acad Med 2004;79:139-143.

2. Maniaci MJ, Heckman MG, Dawson NL. Increasing a patient's ability to identify his or her attending physician using a patient room display. Arch Intern Med 2010;170: 1084-1085.
3. Arora V, Gangireddy S, Mehrotra A, Ginde R, Tormey M, Meltzer D. Ability of hospitalized patients to identify their in-hospital physicians. Arch Intern Med 2009;169:199-201.

4. Hemphill RR, Santen SA, Rountree CB, Szmit AR. Patients' understanding of the roles of interns, residents, and attending physicians in the emergency department. Acad Emerg Med 1999;6:339-344.

5. Francis JJ, Pankratz VS, Huddleston JM. Patient satisfaction associated with correct identification of physician's photographs. Mayo Clin Proc 2001;76:604-608.

6. Dudas RA, Lemerman H, Barone M, Serwint JR. PHACES (Photographs of Academic Clinicians and Their Educational Status): a tool to improve delivery of familycentered care. Acad Pediatr 2010;10:138-145.

7. Mercer MP, Hernandez-Boussard T, Mahadevan SV, Strehlow MC. Physician identification and patient satisfaction in the emergency department: are they related? J Emerg Med 2014;46:711-718.

8. Shan L, Li Y, Ding D, et al. Patient satisfaction with hospital inpatient care: effects of trust, medical insurance and perceived quality of care. PLoS One 2016;11:e0164366.

9. Shimp K, Sims A. Photo identification on a medical-surgical unit improves communication resulting in positive patient outcomes, Nurs Econ 2016;34:309-311. 


\section{Neurology}

\section{Education Research: Physician identification and patient satisfaction on an academic neurology inpatient service}

Christopher R. Leon Guerrero, Tracy Anderson and Allyson R. Zazulia

Neurology 2018;90;e632-e636 Published Online before print January 19, 2018

DOI 10.1212/WNL.0000000000004961

\section{This information is current as of January 19, 2018}

\section{Updated Information \&} Services

References

Citations

Subspecialty Collections

Permissions \& Licensing

Reprints including high resolution figures, can be found at: http://n.neurology.org/content/90/7/e632.full

This article cites 9 articles, 0 of which you can access for free at: http://n.neurology.org/content/90/7/e632.full\#ref-list-1

This article has been cited by 1 HighWire-hosted articles: http://n.neurology.org/content/90/7/e632.full\#\#otherarticles

This article, along with others on similar topics, appears in the following collection(s):

\section{All Education}

http://n.neurology.org/cgi/collection/all_education

All Health Services Research

http://n.neurology.org/cgi/collection/all_health_services_research

Information about reproducing this article in parts (figures,tables) or in its entirety can be found online at:

http://www.neurology.org/about/about_the_journal\#permissions

Information about ordering reprints can be found online:

http://n.neurology.org/subscribers/advertise

Neurology ${ }^{\circledR}$ is the official journal of the American Academy of Neurology. Published continuously since 1951, it is now a weekly with 48 issues per year. Copyright @ 2018 American Academy of Neurology. All rights reserved. Print ISSN: 0028-3878. Online ISSN: 1526-632X.

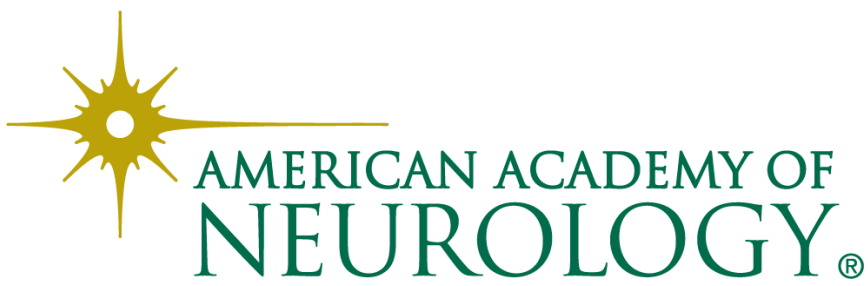

